\title{
Patent Considerations When Embarking on New Antisense Drug Programs
}

\author{
Laurence D. S. Gainey
}

\begin{abstract}
The aim of this chapter is to provide some key information on patents and the patent system to assist someone embarking on the design, development, and commercialization of new antisense drugs.

Here I outline certain key topics such as what is a patent? why patent? how do I protect my molecule with a patent? confidentiality, searching for the same or similar molecules in the prior art, data requirements, the patenting timeline and freedom to operate.
\end{abstract}

Keywords Patent, Intellectual property, Patentability, Prior art, Searching, Patent filing, Exclusivity, Freedom to operate, Confidentiality

\section{Introduction}

When embarking on a research and development program for any therapeutic, including an antisense drug, it is crucial that appropriate consideration be given to patents and the patent system. A patent protecting a therapeutic is often the main tool to keep bioequivalent versions off the market for a limited period, thus allowing the innovator time to recoup and secure a return on their investment. It is also important to consider third-party patents in case these impede the ability to commercialize the therapeutic.

The aim of this chapter is to provide a basic understanding of the patent system for someone embarking on a research program to discover and develop a therapeutic antisense drug. However, as patent decisions for any particular project will be case specific, appropriate legal advice should be sought from a qualified patent attorney.

The chapter is split into sections that discuss:

- What is a patent?

- Why patent inventions?

- Types of inventions to consider. 
- Patenting requirements.

- Importance of confidentiality.

- Patent timeline.

- Data requirements.

- Searching.

- Freedom to operate considerations.

The patenting of a putative therapeutic molecule is usually crucial to the commercial success of the therapeutic. It is therefore recommended that you engage the services of a patent professional with expertise in handling antisense oligonucleotide patent portfolios at the earliest opportunity and keep them appraised of developments in the research program throughout.

\section{What Is a Patent?}

A patent is a property right given by a country's government to an inventor, or their successor, that protects a new and useful invention. It is a reward for publishing the invention and provides the recipient with an exclusive right, for a limited period of time, to prevent others from exploiting, such as making, using, importing, offering for sale or selling, the invention in the country. Once this period of exclusivity has expired the public are free to exploit the invention and this arrangement with the state-a limited period of exclusivity in exchange for publishing and teaching the world what the invention is, is often referred to as the "patent bargain" and is what helps to stimulate and drive innovation.

Some important features of a patent are:

1. It is a country-specific right. Anyone wishing to secure patent protection in multiple countries will need to secure a granted patent in each of these countries.

2. The period of time (often referred to as "the term") of the right is governed by the patent legislation in the country, but in the vast majority of countries, this is 20 years from the filing date of the patent application. Certain countries also have provisions to extend the term of the patent or award a separate extension right, typically for a maximum of 5 years, for pharmaceutical or agrochemical products that were required to undergo regulatory approval.

3. The exclusive right is an exclusionary right. It does not necessarily allow the owner to work (use) the invention. It merely allows them to prevent others from working the invention. For example, if the patent is to a new therapeutic compound the patent does not give you the right to make and sell the compound as this will require separate approval from the health 
authority. Also, exploitation of the invention may fall within the scope of someone else's patent and so authorization, such as via a license, from this entity may be needed to work the invention.

4. The patent right must be applied for via the filing of a patent application that describes the invention in enough detail so that the invention can be understood and reproduced by a skilled reader.

5. A patent is only enforceable (via the relevant national court system) once it has been examined and granted by the patent office of the relevant country.

6. The invention is defined by a series of sentences termed "claims" that describe the invention and help to define the scope of protection (i.e., whether something falls within the patent or not). An analogy for the claims in a patent is the boundary fence that defines a field.

7. The claimed invention must meet certain requirements to become a "granted patent"—-see Sect. 5 .

\section{Why Patent Inventions?}

The cost of research and development (R\&D) for therapeutic molecules is significant. In 2016, the Tufts Center for Drug Development estimated R\&D costs per approved drug to be in excess of $\$ 2.5$ bn [1]. In order to drive investment in therapeutic R\&D there must be means to recoup and provide a return on this investment. The patent system has evolved to stimulate innovation and is one of the key mechanisms to provide an environment for securing a return on the investment.

3.1 Exclusive Market Position
Patents provide a legal right to stop others from working a patented invention for a period of time. Provided the patent owner or their licensee has all other necessary freedom to operate, it can mean that they can establish exclusivity to sell their product in the market.

During this period of exclusivity, when there is no direct competition for the same product, it is often easier to commercialize the product and so recoup the costs invested in the R\&D and obtain a return on that investment.

A patent is a property right which can be sold or licensed to another party. In exchange for granting a licensee the rights to work under the patent, the applicant/licensor can secure financial or other compensation. This means that patent owners who are unable to fully exploit the invention independently can, for example, leverage the patent for revenue, cross-licensing purposes and/or open up valuable collaborations. Thus, a patent protecting a therapeutic 


\subsection{Collateral for Raising Funding}

3.4 Incentive to Invest in Research and Development antisense oligonucleotide product or its use can also be very valuable to individual inventors, small companies, and academic institutions.

Because of the opportunity to secure an exclusive market position as in Sect. 3.1, a strong patent portfolio is attractive to investors and so can assist with company flotations or raising further capital.

Without the existence of a patent protecting a therapeutic antisense oligonucleotide molecule or its use in treating a particular disease or patient group, there may be significant disincentives to invest in the research and development costs and lost commercial opportunities.

\section{Types of Inventions to Consider}

A patent protecting the oligonucleotide drug molecule being developed, often defined by its sequence, is likely to be particularly desirable as this will protect the molecule regardless how it is used.

However, in addition to a new oligonucleotide defined by its sequence and/or particular chemical modifications (e.g., to the backbone, sugars, bases) throughout or at specific positions, it is important to recognize that valuable patenting opportunities might also be found for new types of chemical modifications, fusions or conjugates, manufacturing processes, formulations, drug delivery technologies, particular diseases to be treated (therapeutic uses), particular patient populations to target, dosage forms of the drug, and/or dosage treatment regimens, to name just some categories of invention. It is therefore important to think beyond the specific molecule/compound to see if there are other patentable opportunities that can be captured to enhance the patent portfolio protecting your entire research program.

\section{Patenting Requirements}

Each country (jurisdiction) has its own legal requirements (legislation) of what constitutes a patentable invention, but typically the claims that define the invention must meet certain criteria, including (1) novelty (new); (2) inventive step (not obvious) over what is already known; and (3) industrial utility (be useful). In addition, the application must include an adequate description of how to carry out the invention.

Individual country legislation may also preclude the patenting of certain types of subject matter in that country. For example, certain countries do not permit patents directed to methods of treatment, surgery or diagnosis practised on the buman body. 
However, antisense oligonucleotide molecules, particularly those with chemical modifications, constitute patentable subject matter all the key countries (including US, Europe, Japan, China).

\subsection{Novelty}

The claimed invention must not have been disclosed in the public domain prior to the filing date of the invention.

According to Article 54(1) of the European Patent Convention [2]:

\section{An invention shall be considered to be new if it does not form part of the state of the art.}

Thus, a claimed invention is novel/new if it does not form part of "the state of the art," the state of the art being everything that was available to the public by way of written (including via electronic means) or oral publication, use or any other way, in any country of the world and in any language before the effective filing date of the invention. The effective filing date of the invention is the date of filing of the first patent application (e.g., priority application or International application-see $7(\mathrm{~b})$ ) that appropriately discloses the claimed invention. Novelty is an objective measure. Each and every feature of the claimed invention must have been disclosed together in the prior art to preclude patenting based on novelty.

An ideal antisense molecule may be the culmination of optimum choice of a number of features including, target sequence, length, complementarity, and chemistry. Thus, even with recognized therapeutic targets, there is often scope for establishing novelty over the prior art molecules. What will likely determine the ability to secure a patent on the molecule will be inventive step or non-obviousness.

5.2 Inventive Step (or Non-Obviousness)
It is somewhat subjective, and the assessment of inventive step differs from one country to another but, in essence, it is an assessment of whether the difference between the claimed invention and the state of the art, as assessed by the person skilled in the art, is obvious.

According to Article 56, first sentence, of the European Patent Convention [2]:

An invention shall be considered as involving an inventive step if, having regard to the state of the art, it is not obvious to a person skilled in the art.

Because this assessment is to be made by the notional "person skilled in the art," it is intrinsically more difficult to gauge whether a claimed invention is inventive and is the main discussion point between a patent examiner and the patent attorney seeking to secure grant of the patent.

However, indicators of inventive step accepted by most patent offices include surprising and/or unpredictable results. To demonstrate this, it will likely be necessary to have comparative data which 


\subsection{Industrial Utility}

\subsection{Sufficiency/ Written Description}

demonstrates that the new antisense molecule, as claimed, possesses some superior property, perhaps much greater affinity or half-life, compared to that of the closest prior art molecule.

The claimed invention must be capable of being made or used in any type of industry.

According to Article 57 or the European Patent Convention [2]:

An invention shall be considered as susceptible of industrial application if it can be made or used in any kind of industry, including agriculture.

In general, this is an easy criterion to meet, and it is difficult to see how an antisense oligonucleotide invention would not meet this requirement.

Finally, the application must include sufficient information to allow the person skilled in the art to work the invention across the whole area claimed without undue burden or requiring inventive skill.

According to Article 83 or the European Patent Convention [2]:

The European patent application shall disclose the invention in a manner sufficiently clear and complete for it to be carried out by a person skilled in the art.

Similar or equivalent provisions to those above, illustrated using the European Patent Convention [2], are to be found in the patent legislation of most counties.

\section{Confidentiality}

As noted above, to be patentable an invention must be novel.

The invention must therefore have not been disclosed to anyone outside of a confidentiality agreement or put into the public domain by any means. Numerous patent applications have failed to meet the novelty or inventive step criteria due to an inventor's own disclosure/publication.

Aside from publication in a scientific journal, other publications to be aware of include, website postings, or poster or oral presentation at a scientific conference. If the researcher is from an academic institution, other potential publications include: an internal academic presentation attended by individuals from outside the institution or under no obligation of confidentiality, a $\mathrm{PhD}$ thesis, a discussion with an academic from a different institution, indeed any oral disclosure to someone not required in law to keep the information confidential.

While some countries, such as USA, provide for a "grace period" that allow prior publications from the inventor, made 
within a limited period before the filing date of their patent application, to be discounted from the prior art when assessing patentability, thus allowing a patent application to be filed after an earlier publication, it is a mistake to rely on this facility because "grace period" provisions only exist in a few countries. As noted above, therapeutic drug development costs are very high. In order to recoup such investment, it is typically desirable or necessary to be able to sell the drug globally, and thus important that patent protection for the drug be secured in the major markets. Many of the major pharmaceutical market countries do not have a grace period provision. An ill-timed publication could therefore undermine the opportunity to secure a patent in certain of the major markets which will have serious commercial implications. For example, it may dissuade a potential licensee or could be a reason for ceasing development of the molecule.

It is therefore crucial that the invention is kept confidential, at least until the patent application has been filed (see Note 1).

\section{Patent Timeline}

There are various routes available for seeking a patent in a particular country.

However, in situations where the applicant desires patent protection in multiple countries the following route is commonly adopted:

(a) First filing of a patent application in a reference country, typically the home country of the applicant. This first application is often referred to as the priority application. Optionally, one or more subsequent priority application filings may follow within the next 12 -month period.

(b) At or prior to the 12-month anniversary of the first priority application a single application claiming priority from the earlier priority application(s) is filed under the Patent Co-operation Treaty (often referred to as a PCT or international application). By designating all available states in the PCT application, it is possible to convert this single international application into separate national patents in most countries of the world.

(c) A search and preliminary non-binding opinion on the patentability of the claims is carried out by the patent office processing the PCT application and sent to the applicant, typically around 16 months from the filing of the earliest priority application.

(d) 18 months from filing of the earliest priority application the PCT application is published. 
(e) Typically, at 30 months from the earliest priority date (see Note 2) the applicant must convert the international (PCT) application into separate national or regional applications (see Note 3). At this stage, the PCT application ceases to exist.

(f) The national or regional applications are then examined by each respective national or regional patent office. Such examination will typically take $2-8$ years culminating either in grant of the national or regional patent or refusal. On grant of a regional patent the applicant must then decide which countries within the region to convert the patent into. These then become national patents.

(g) During the term of the regional or national patent applications or granted patents, it is typically necessary to pay ongoing fees (typically referred to as annuity or renewal fees) for keeping the application/patent in force. The term of any granted national patent is typically 20 years from the filing date (using the PCT system described above, the PCT application filing date in (b)).

(h) In some countries, certain pharmaceutical or agrochemical patents may be entitled to a patent term extension for up to 5 years from the normal expiry date of the national patent. In Europe, rather than a patent term extension, a separate intellectual property right termed a Supplementary Protection Certificate (SPC) with a term of up to 5 years may be available. The patent extension or SPC referred to herein is to compensate, in part, for the period of time that the pharmaceutical or agrochemical compound was subjected to regulatory assessment by the authority responsible for regulating such products.

A typical timeline that uses the PCT system outlined above is shown in Fig. 1.

More details on the PCT system can be found on the PCT website [3].

\section{Data Requirements}

Patent attorneys are often asked how much and what type of data must be included in the patent application. There is no hard and fast rule on this. Generally, it is case specific and will depend on various factors such as the complexity in the art.

The majority of patent systems typically do not mandate that the patent application contain any number of specific examples, nor that these examples be actual worked examples with real data. However, in order to be patentable, the invention must be sufficiently described and enabled (or supported) to permit a person of 


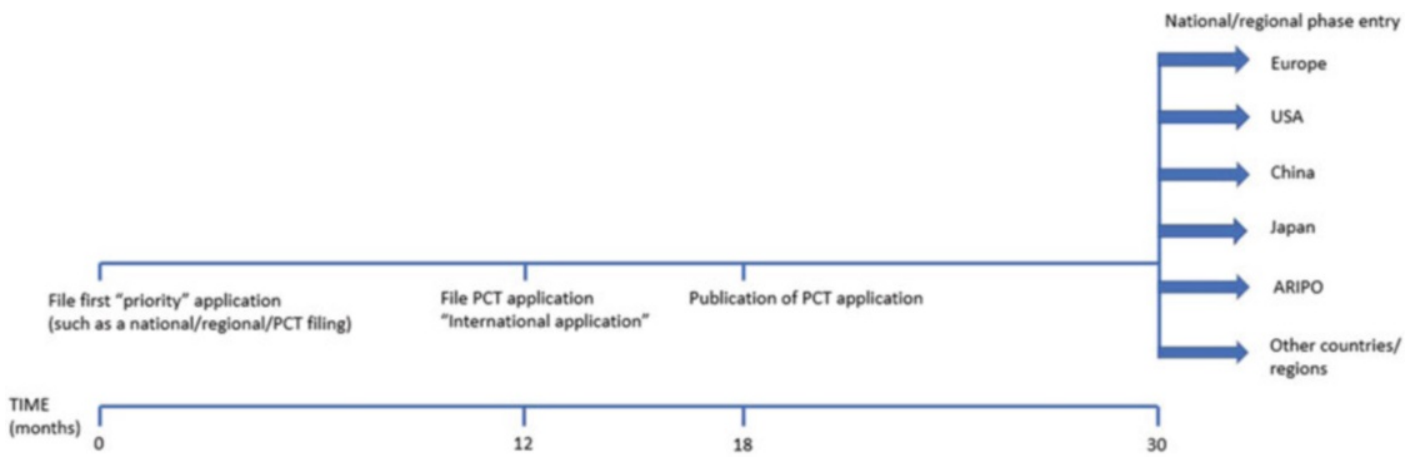

Fig. 1 Basic timeline for Patent Cooperation Treaty (PCT) patent application filling

skill in the art to practice the invention. With predictable technologies, such as mechanical devices, disclosure of a single means for making or using the invention may suffice. The person skilled in the art can easily make the invention and understand whether and how it works. In more unpredictable fields, such as therapeutic agents acting within biological systems, it is likely that the amount and type of data needed to demonstrate that the invention works and that the person skilled in the art can practice the invention will be greater. Thus, in practice, with therapeutic-type inventions, the presence of worked examples with relevant data plays a significant part in satisfying the patent examiner (and/or court) that the invention as claimed is supported/enabled and works.

Antisense oligonucleotide inventions, as with other therapeutic molecules, particularly those in established fields would benefit from two categories of data.

The first are data that would convince the person skilled in the art that the molecule has the necessary biological effect to make it credible that it would work as claimed (supporting data). Thus, if a disease pathology is manifest by expression of a particular protein, data demonstrating that the antisense oligonucleotide can, for example, impede production of the protein would be advantageous.

It is not necessary that the application include actual clinical trial data demonstrating efficacy in the relevant subjects (e.g., human patients). Suitable in vivo or ex vivo animal data or even cell data from an in vitro system, demonstrating that the antisense molecule impedes protein production, for example, may be sufficient and should be included in the patent application.

The second are data that demonstrate that the claimed invention performs better than what is already known (comparative data). Comparative data is particularly helpful, indeed often necessary, if the claimed invention is close to and thus potentially prima facie obvious over what is already known (in the public domain). Data comparing the claimed invention with the closest prior art 
molecule can help support the position that the claimed invention meets the inventive step (non-obviousness) criterion.

While it may be possible to supply this comparative data during the patent examination/prosecution stage it is advantageous to have this in the application as filed. However, in order to be able to do this, the researcher must have identified which molecule is likely to be determined to be the "closest prior art molecule" and then to have synthesized and tested this molecule against those of the claimed invention.

\section{Searching}

As will be appreciated from the above, the claimed invention is assessed against what is already known (in the public domain).

When embarking on a research program for a new antisense oligonucleotide, it is recommended that the researcher conduct or commission searches of the published literature, including published patent applications, to identify, for example, the various molecules against the target sequence that are in the public domain. This information can assist on two fronts. First, it offers the opportunity to conduct research in novel space and design novel molecules; secondly, it should identify the molecule(s) that are likely to be considered the closest prior art molecules against which the new molecule with be assessed for patentability.

Prior art and patent searching is a skill that requires access to and an understanding of how to search particular databases of published documents. The ways of conducting searches of the prior art is beyond the scope of this chapter. The researcher may have the tools (e.g., databases of publications) and skills to conduct their own prior art searching. Otherwise, it is recommended that this be commissioned from an appropriate search firm.

\section{Freedom to Operate (FTO)}

The final topic to flag is that of freedom to operate. As noted above, a patent on your product (e.g., antisense oligonucleotide drug) is an exclusionary right. It does not give the right to commercialize the product, and one obstacle to exploitation may be the existence of one or more third-party patents that dominate the ability to make, use or sell the product. Examples of dominating third-party patents might be those that cover a broad class of molecules that your development candidate falls within or claims to the precise therapeutic use (e.g., disease to be treated) that a molecule such as the one you are developing is to be used for.

It is therefore also important to consider third-party patents in case these impede the ability to commercialize the product. An 
FTO assessment for third party patents starts with searching for the existence of relevant pending applications or granted patents. It is highly recommended that such searching be conducted by professional searchers and the search output should then be assessed by a suitably qualified patent attorney. Once potentially relevant thirdparty patent property, both pending applications and granted patents have been identified, strategies to mitigate the risk of patent infringement can be devised. This could include securing legal opinions on infringement and validity, initiating challenges to the validity of such patents and/or securing appropriate patent licenses to any dominating patents.

The most meaningful FTO assessment can only be carried out when the actual product and its method of manufacture have been identified. However, if FTO assessments are carried out at an early stage it may help to gauge risk and potentially allow the design of molecules that avoid problematic third-party patents. For example, if equivalent chemical modifications are feasible, only one of which is protected by third-party patents, it may be possible to utilize the patent-free modification to avoid the FTO risk.

\section{Summary}

When embarking on a research program to develop a therapeutic antisense oligonucleotide, it is important to consider and incorporate a patent strategy that includes seeking protection for patents on the product and being aware of third-party patents that might be an impediment to commercialization.

It is advantageous to conduct prior art searches early on to ensure that your molecule is novel over those already known and to identify the closest prior art molecules against which your product will be assessed for patentability, in particular inventive step. It is imperative that the details of the invention are kept confidential until after the patent application has been filed, at least.

It is important to generate data that demonstrates that the molecule has the biological properties likely to be of use in the purported treatment and to include this data in the patent application. In vitro cell data may be sufficient.

It may also be advantageous to generate comparative data to demonstrate that the claimed molecule has some unexpected beneficial property or improvement over the closest prior art compound. If this data is included in the patent application, it could help to satisfy the patent examiner that the claimed molecule meets the inventive step criterion and thus greatly facilitate the patent prosecution. If it is not available at the time of filing it may be useful, if not actually necessary, to generate this data for use in the patent prosecution stage. 
It is important to recognize that valuable patenting opportunities may exist for subject matter other than the antisense compound itself and its particular use and you should consider whether seeking patent protection for these would strengthening the overall patent portfolio.

Finally, you should engage the services of a patent professional with expertise in handling antisense oligonucleotide patenting at the earliest opportunity. They can provide counsel on the appropriateness of the data generated and the strategy for filing and prosecuting the patent application(s), including which territories to pursue for patent protection. They can draft and file the patent application(s) and manage the patent portfolio. They can also assist with any necessary prior art or third-party patent searching and advise on the best time to undertake the necessary freedom to operate assessments.

\section{Glossary}

Applicant - the individual or legal entity that has filed for and has claimed initial ownership of a patent application.

Freedom to operate (FTO)-is the ability to develop, make, sell, offer for sale (i.e., market) the product without legal liabilities to third parties, including third party patent owners.

Licensor - the person or entity that grants formal permission to make or do something. In the context of a patent the right to perform certain acts protected by the patent.

Licensee - the individual who obtains the license from the licensor to make or do something.

Patent claims - a series of independent or linked (dependent) sentences that define the scope of what is being claimed as the invention. The patent claims form one section of the patent application.

Patent Cooperation Treaty (PCT) - is an international patent law treaty which provides a unified procedure for filing patent applications in each of its contracting states. It is administered under the auspices of the World Intellectual Property Organization (WIPO). A patent application filed under the PCT is typically referred to as an international application, or PCT application. The PCT application is merely a vehicle to facilitate grant of individual national patents. It is not, and cannot, become a patent itself. There is no such thing as an international patent.

Patent office - is a governmental or intergovernmental organization which processes and awards patents. 
Patent portfolio-refers to the collection of patent applications and granted patents owned by an applicant.

Patent prosecution - is the process taken to establish whether the patent application meets the criteria for grant of a patent. It may also be referred to as patent examination.

Patent term (or "term") - is the length or period of time that a patent can remain in force. Once this term has finished the patent expires and the invention enters the public domain, so anyone is entitled to freely exploit the invention.

Patent term extension - is an extension of time to the usual patent term.

Person skilled in the art-is a fictitious individual used in many patent laws of the world as the individual that is used as reference to determine whether the claimed invention is patentable (e.g., inventive) and the application sufficiently disclosed, among other things. Often the person skilled in the art is a technician skilled in the technical area of the invention who is aware of the prior art and has common general knowledge but no scintilla of ingenuity or inventiveness. Sometimes the person skilled in the art can be a team of individuals. It is a legal fiction.

Prior art-refers to all information that has been made available to the public prior to the effective filing date of the claimed invention. The effective filing date being the date of filing of the application that first discloses the claimed invention. This could be, for example, the date of one of the priority applications or the substantive application.

Priority application or priority patent application - a patent application filed in a national or regional state (including PCT application) that can be used to claim priority to from a subsequently filed national, regional or international application.

Public domain - refers to information or inventions which are freely available to the public, in particular, where no exclusive intellectual property rights exist or are possible. It can refer to patented inventions whose term has expired or information which has been published and so no longer protectable by a patent.

State of the art - refers to information which is known, or is capable of being known, by the public. It is often a synonym for prior art (information known before the patent filing date).

Substantive application - is the national or international application which will be subjected to patent examination and whose text can no longer be changed. Such filing may claim priority from an earlier "priority" application. 
Supplementary Protection Certificate (SPC) -is a distinct intellectual property right available in countries of the European Economic Area that extends the term of certain rights under a patent for pharmaceutical or agrochemical products that have had to undergo regulatory assessment. It enters into force immediately the patent on which it is based expires. The SPC is designed to compensate the applicant for delays incurred in securing regulatory approval for a product, and it effectively extends the monopoly right for the product for a limited period of time.

\section{Notes}

1. There may be advantages to delaying publication until the substantive application filing date or even the patent application publication date, and these should be discussed with your patent professional.

2. The time limit to enter the national phase for most states/ countries signed up to the PCT is 30 months from the priority date; however, the patent legislation of a country or region may set a time limit which expires later than 30 months from the priority date.

3. There are four regional contracting states to the PCT: African Regional Intellectual Property Organization (ARIPO), Eurasian Patent Office (EAPO), European Patent Office (EPO), and African Intellectual Property Organization (OAPI).

\section{References}

1. DiMasi JA, Grabowski HG, Hansen RW (2016) Innovation in the pharmaceutical industry: new estimates of R\&D costs. J Health Econ 47: 20-33. https://doi.org/10.1016/j.jhealeco. 2016.01 .012
2. European patent convention (2016) ISBN 978-3-89605-152-3

3. International Patent System website (2021). https://www.wipo.int/pct/en/

Open Access This chapter is licensed under the terms of the Creative Commons Attribution 4.0 International License (http://creativecommons.org/licenses/by/4.0/), which permits use, sharing, adaptation, distribution and reproduction in any medium or format, as long as you give appropriate credit to the original author(s) and the source, provide a link to the Creative Commons license and indicate if changes were made.

The images or other third party material in this chapter are included in the chapter's Creative Commons license, unless indicated otherwise in a credit line to the material. If material is not included in the chapter's Creative Commons license and your intended use is not permitted by statutory regulation or exceeds the permitted use, you will need to obtain permission directly from the copyright holder. 